\title{
Empowering formative assessment using embedded Web Widgets in Wikis
}

\author{
Michele Notari \\ PHBern, University of Teacher \\ Education \\ Muesmattstrasse 29 \\ 3012 Bern, Switzerland \\ michele.notari@phbern.ch
}

\author{
Sonja Schär \\ PHBern, University of Teacher \\ Education \\ Muesmattstrasse 29 \\ 3012 Bern, Switzerland \\ sonja.schaer@phbern.ch
}

\author{
Martin Schellenberg \\ PHBern, University of Teacher \\ Education \\ Muesmattstrasse 29 \\ 3012 Bern. Switzerland \\ martin.schellenberg@gmail.com
}

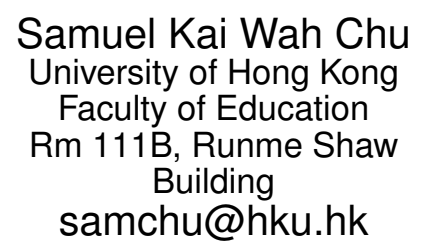

\begin{abstract}
In this article we describe how we developed and how we use a tool for teachers enhancing inter-group collaboration of learners using wikis in project-based learning settings with over 100 participants, where different groups of students develop similar projects and each project has an own wiki page. To achieve our goal we extended typical wiki functionality by using web widgets, mini applications embedded anywhere in the wiki environment using the iframe tag.

Two different evaluation widgets (rating widget and 'working progress' widget) are placed on each of the project pages. The project groups use the "working progress' widget to declare the amount of work done. The teacher and the rest of the learning community use the 'rating' widget to rate the ongoing project work. A so called 'meta widget' showing a summary of the results of the 'rating' and "working progress' widget can be displayed on the start page of the learning community or if a project is divided in different milestones, on the page describing the goals and timeline for the milestone. Evaluation widgets and meta widget, which easily can be embedded by the teacher potentially all over the wiki pages, enhances visibility of quality and termination degree of a project and enhance so the self, the tutor and the peer review opportunities in such large scale project based learning settings. The created evaluation widgets and meta widgets have been embedded in the wiki of a three months curriculum. The evaluation of utility and usability of the widgets is ongoing. The educational value of rating and reflecting about the working progress of a given task is discussed.
\end{abstract}

\section{Categories and Subject Descriptors}

K.3.1 [Computer Uses in Education]: Collaborative learning; H.3.5 [Online Information Services]: Web-based Services; H.5.3 [Group and Organization Interfaces]: Computer-supported cooperative work, web-based interaction

\section{Keywords}

web widget, formative evaluation, collaboration, projectbased learning, long term projects, inter-group collaboration, large scale collaboration

\section{WIKIS IN EDUCATION}

Wikis, the simplest form of content management systems, were invented by Ward Cunningham in 1995 [8]. It didn't take long until their potential for education was discovered [7]. A wiki may be defined as follows: "A wiki is a web server with version control on the Internet, where everybody can create, change, and link web pages without additional tools and without HTML knowledge" [4]. Using this definition, some of the potentials of wikis can be described as following [11]:

- Create: Creating content activates and motivates learners, two important prerequisites for learning

- Change: Wikis ease the modification of content (like all computer-based editors). This allows for more revisions of a text which fosters re-reading and re-thinking the text and therefore can enhance the learning effect.

- Link: Wikis allow links between different parts of a text (see all hypertext systems). This requires that learners read and understand the parts they want to link and find fitting relationships. This enhances the discussion about the topic.

- Everybody: Wikis ease collaborative content creation and therefore ease working in interest-groups.

\footnotetext{
Permission to make digital or hard copies of all or part of this work for personal or classroom use is granted without fee provided that copies are not made or distributed for profit or commercial advantage and that copies bear this notice and the full citation on the first page. To copy otherwise, to republish, to post on servers or to redistribute to lists, requires prior specific permission and/or a fee.

WikiSym '13 August 05-07 2013, Hong Kong, China ACM 978-1-4503-1852-5/8/13.
} 
- Revision control: (so called history pages) The integrated revision control of wikis not only lowers the danger and damage of vandalism. The revision control can also be used to look at the creation process by the teacher and the students. This can foster reflection about working and learning strategies.

- On the internet: As wikis can be hosted on a server on the internet, schools don't have to install hardware in their own buildings and the wiki can be accessed from everywhere.

- Without additional tools: As wikis only need a web browser as a tool, there is no need for more software installation on the learners computers. This lowers the barriers for using wikis as a learning tool.

Wikis in education are often used in order to support collaborative and constructive learning approaches [13]. In wiki based learning processes learners produce specific text and media artifacts, publish them in predefined pages of the wiki. The described wiki functionalities enables the learners to see how their produced artifact evolves and to compare the text of all members of the learning community [10]. It turns out to be important to see what peers have written in order to situate the quality and appropriateness of the own texts. In contrast to the wikipedia community, where many persons usually focus on one single article, in a formal collaborative learning setting it is essential for the learning process, that the single learner keeps an overview of the whole growing text.

The question rises how to help the learner to keep an overview of the working progress and the quality of the ongoing inputs of the whole learning community. The proposed tool visualizes the perceived quality and amount performed work of each learner (learning group) by keeping the additional workload for the single learner as small as possible. The proposed visualization elements (perceived quality of produced artifacts, working progress and summary of quality and working progress) enhance formative assessment opportunities throughout the curriculum. We hope to help learners keeping an overview of relevant information for the individual learning process, inducing them to read and compare their ongoing work with relevant inputs of other learners. The created tool can also help the teacher to get a better overview the artifact creation process within the used wiki.

\section{THE IMPORTANCE OF FORMATIVE AS- SESSMENT FOR LEARNING}

Blackand William [2] describe formative assessment as: "The distinguishing characteristic of formative assessment is that the assessment information is used, by the teacher and pupils, to modify their work in order to make it more effective." Based on the 'Black Box' research of Black and Wiliam [1] formative assessment has the following effect:

- Pupils learn more effectively

- Some pupils feel more involved in the schooling process and become less disaffected

- Teaching is focussed more effectively on the individual pupil
- Positive effects may be particularly evident in the less able

- Learning in the wider (not subject-specific) sense can be enhanced

Concerning self assessment, Clarke [3] states that students should make judgements themselves about their progress toward targets and that low achievers can benefit from selfmonitoring. Further, Dylan and Thompson [6] propose three central processes to build a framework for formative assessment, namely: establishing where learners are in their learning process, establishing where they are going to and establishing how to get there.

\section{MANAGING FORMATIVE ASSESSMENT THROUGH INTER AND INTRA-GROUP COLLABORATION IN LARGE LEARN- ING COMMUNITIES}

Using a collaborative web page as a wiki per se opens a lot of different opportunities to perform formative assessment within a learning process. The visibility of all the written work in progress of a learning community, the possibility to link similar pages and concepts, the version control, which permits to see the evolution of any single page and the built in discussion and comment functionalities permit in connection with the appropriate didactic approach a high quality and efficient interchange of ideas [12].

In collaborative learning settings, where learners work in different groups, intra-group collaboration usually takes place within a single wiki page and so formative assessment can easily be managed using the implemented wiki functionality. Inter-group collaboration becomes more difficult in a wiki where many learning groups generate inputs on many different pages. Specific didactic settings where on a given point learners have to read contribution of others and compare and rate other works enhance inter-group collaboration. At the same time such interventions also enhance formative assessment. Beside of specific interventions proposed by the teacher additional functionalities of the wiki engine can induce formative assessment elements.

\subsection{Web widgets}

Introducing an additional functionality within the wiki which shows quality and performed work enables the single learner a quick orientation within the different pages and different group activities. Such a visualisation helps managing formative assessment especially in project-based learning setting where different groups work parallelly on similar topics. For that purpose we developed so called web widgets permitting learners to easily find qualitative good projects and find out which project groups already performed specific tasks. The idea of web widget was already used by Doorn and Eliens in [16] to describe a possibility to bring applications in the world wide web. Also other terms are used e.g. gadgets (e.g by Google), modules or badges. We use the term web widget and our definition of web widgets follows the definition of web widgets of the W3C as described in Widgets 1.0: The Widget Landscape, Chapter 3.1 [18].

Typically, a web widget is a mini application that can be embedded in a website. Simple copying a piece of code and pasting it to the right place of a web site installs the widget. Therefore end users and webmasters allowed to change the 
content of a web site can embed a widget. Of course, the simple usage of web widgets makes them very suitable to use on personal publishing space like blogs or as in our case in a wiki.

Web widgets can be used in wikis because modern wiki engines like MediaWiki (http://www.mediawiki.org) or Wikispaces wiki (http://www.wikispaces.com) allow the direct embedding of 'chunks' of html code or java script. For example the iframe-tag can be used to include content of an external website. In Wikispaces the user can include the code in the normal wiki editor, using the "other html widget". MediaWiki provides several extensions for the purpose of embedding html code or javascript. One of them is the gadgets extension. Of course it is possible to embed the web widgets on any wiki page and anywhere on the pages.

Since the web widget is a small application, it adds additional functionality, interactivity or information to a website. Typically, the functionality of the web widget is clearly defined and limited to a particular topic. Well known examples for web widgets are widgets for weather forecasts, news headlines, Facebook friend lists or clocks.

As mentioned above, a web widget is embedded on a web site. But the actual widget is hosted on the web server of the provider of the widget. So all data is stored on the providers server but showed on the users web page. This architecture also implies that the user creates the web widget on the providers web page. Mostly it is possible to configure the web widget before creation. After creation, the code to copy is shown on the web page.

\subsection{Using Web Widgets for inter-group col- laboration}

On one hand we want to visualize the quality of created artifacts and on the other hand the progress of the work done in a project as described in Section 3. For this purpose we developed two evaluation widgets. First a widget which delivers information concerning the quality of the project or artifact (rating widget; see Figure 1) and second a project state widget type (working process; Figure 2), which shows which percentage of a specific milestone of the project has been fulfilled. These two widgets are placed on each project page within the course wiki. The rating widget is supposed to be used by non group members, while the widget showing the ongoing work within a milestone is supposed to be used by the project group.

In big learning communities, where a lot of artifacts on many different pages are created, it is essential for the learner to get an overview of the work of all groups (see Section 3). Providing this overview is the main contribution of our work. A meta widget (see Figure 3) has been programmed in order to create a visualisation of all evaluation widgets of all project groups. This 'meta widged' is placed on the main page of the wiki permitting all learners to see the rating and working progress of all project groups at a glance.

\section{की \\ Rating: 8 (1 votes)}

FigURE 1. rating widget (evaluation widget)
Geben sie an, wie viel Prozent des

Projektes Sie schon erarbeitet haben.

$100 \%$

(a) dropdown for the input

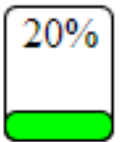

(b) read

only view

FIGURE 2. working progress widget (evaluation widget)

\begin{tabular}{|c|c|c|c|c|}
\hline \multicolumn{5}{|c|}{ 12HS - Video } \\
\hline Bereich & Konzept & Projekt & Konzept & Projekt \\
\hline Typ & Bewertung & Bewertung & Meilenstein & Meilenstein \\
\hline V-1-1_12 & $0 / 10$ & $0 / 10$ & $100 \%$ & $100 \%$ \\
\hline V-1-2_12 & $10 / 10$ & $0 / 10$ & $100 \%$ & $100 \%$ \\
\hline V-1-3_12 & $0 / 10$ & $10 / 10$ & $100 \%$ & $100 \%$ \\
\hline V-2-1_12 & $9 / 10$ & $0 / 10$ & $100 \%$ & $100 \%$ \\
\hline V-2-2_12 & $7 / 10$ & $0 / 10$ & $100 \%$ & $100 \%$ \\
\hline V-2-3_12 & $8 / 10$ & $0 / 10$ & $100 \%$ & $100 \%$ \\
\hline V-3-1_12 & $0 / 10$ & $0 / 10$ & $100 \%$ & $100 \%$ \\
\hline V-3-2_12 & $8 / 10$ & $10 / 10$ & $0 \%$ & $100 \%$ \\
\hline
\end{tabular}

FiguRE 3. Meta widget: the top rows shows the different milestones and the evaluation widgets (Bewertung = rating; Meilenstein $=$ Working progress). The columns display the different project groups

\section{IMPLEMENTATION OF THE EVALUA- TION WIDGETS AND THE META WID- GET}

In this section we first describe our requirements for the evaluation widgets and especially the meta widget. Second we answer the question why we decided to implement our own web widgets instead of using existing ones. And third, we describe our implementation and the used tools and techniques.

\subsection{Requirements}

For the rating widget we want to have a typical layout with five stars. Some of the stars are gray, others colored. The portion of colored stars equates the rating. Rating is done by clicking one of the stars. The rating widget is shown in Figure 1. The working progress widget consists of an input of percentage values. A dropdown box is a simple 
possibility to do so. See Figure 2 for the working progress widget. So the requirements for both evaluation widgets are quite straightforward.

For each evaluation widget we store of course the actual results in the database. These are:

- rating in total

- number of ratings

- percentage of work done

Additional we need for every widget a identifier consisting of a name e.g. "group1rating2". The name is set by the teacher when creating the widget.

There are two main requirements for the meta widget. First it has to be configurable. The user must have the possibility to choose which widgets he wants to show in a actual meta widget. For example the teacher just wants to show the rating of some groups on a project page. But on the main page he wants to show all ratings of all groups and all projects. Second, the rating as well as the working progress shown in the meta widget must be read only.

Finally we want to embed the evaluation widgets as well as the meta widget anywhere on any wiki page. This process must be simple, so that teachers can use them according to their requirements.

\subsection{Implementation}

There already exist many web widgets for rating. So why didn't we use them instead to implement our own widgets? Plenty of reasons led to this decision. The most important reason is the concept of having a meta widget as described above; giving an overview of the results of the widgets of all groups. It is hardly possible to realize this concept with an existing web widget.

The following description of the possible workflow when using an existing web widget clarifies this point: As described in Section 3.1, an instance of a web widget is created and configured on the web site of the provider of the widget. After configuring a piece of code is showed on the providers web page. This is the code to be embed in the wiki. Now, for example, we want to use a rating widget to rate the work of group one. On the website of the provider we create and configure the widget and copy the code. We then paste this piece of code on the wiki page "work of group one" with the content we want to rate. After saving, the rating widget is now displayed on the wiki page. From now on the learners can rate the work of group one by clicking on one of the stars.

But then we also want to show the rating of the work of all groups on another wiki page, e.g. the project home. Of course this means that we also want to show the rating widget for the work of group one. This implies, that the same web widget we included on the wiki page "work of group one" must be shown on this other page. Therefore we have to include exactly the same code on this page too.

One the one hand this workflow is time-consuming, tedious and error-prone, especially when working with many groups. On the other hand, the existing rating widgets we know do not have a read only view. Therefore it would be possible to rate in the overview table. But since this table normally is not located on the same wiki page as the work, the content to be rated is usually not visible there. So rat- ings in the overview table would be arbitrarily and therefore undesirable.

Besides this argument, there exist another minor reasons against using existing widgets. One is the dependency of a provider. It is not possible to know how long the web widget is still available or how it will change in future. Furthermore its not possible to control or influence its quality. Moreover we will not have direct access to the data, e.g. for statistical analysis. And finally, we found no existing web widget for showing the working progress.

Therefore we decided to implement the web widgets by ourself. We describe the used techniques in the following.

As described in Section 3.1, web widgets are always hosted on the web site of the provider and also the data is stored on the server of the provider. This implies, that we need both a web site and a database to store the data. And of course we have to implement the functionality of the widgets themselves.

We decided to create the web site with PHP 5 and to use a mySql database. The widgets are also implemented with PHP 5, using AJAX and JavaScript. To do so, we use the Yii Framework (http://www.yiiframework.com/). CSS 3 to describe the presentation semantics completes the set of used techniques.

Since our widgets still are a beta release, we create a concrete instance of one of the web widgets by setting the database entries needed. After creating the web widgets we provide the code for embedding in the wiki on our web page. There is code provided for every single widget, once in editable and once in read only mode. Also the code for the meta widget is provided on our web site.

The following example shows the code for the read-only view of a rating widget.

<iframe src="http://widgetserver/index.php/wRating/ get/2001" width="180" height="90" frameborder="0"> $</$ iframe $>$

Fulfilling the requirements, it is possible to configure the master widget. That means, it is possible to choose which evaluation widgets we want to show in a concrete overview. For example we only want to show the rating widgets, or we only want to show all widgets of one group. Also for the meta widget the configuration is done by the provider and not the end user at the moment.

Example of the code of a meta widget:

<iframe src="http://widgetserver/index.php/

superwidget/arrcview/5" frameborder="0"

scrolling="auto" width=" $50 \% "$ height $=" 400 ">$

$</$ iframe $>$

\section{A TYPICAL EXAMPLE OF USE}

In this section we want to state an example of use and the characteristic workflow for both, teachers and learners. In our description we act on the assumption, that we already implemented an user interface for the teachers. The setting we describe is according to a curriculum at the University of Teacher Education, where we used and tested the widgets.

\subsection{Setting}

We embedded the web widgets into the wiki used for a curriculum for 117 lower secondary pre-service teachers. The course lasts about 8 months. During the first four months, the project was prepared in 'traditional lessons'. Afterwards the students worked in project groups of three or four per- 
sons, creating a project focussing audio, image processing, print or video as medium. The total workload for this course was 90 hours; the project work has been graded at the end of the course. A Wikispaces environment was used during the whole curriculum to display course related information like goal of the curriculum, timeline, scaffolding elements and deliverables. The wiki has also been used by the students to publish all elements of their project like project outline, all produced media artifacts and the final project work. During the whole curriculum all students had access to the ongoing projects of the whole learning community. In different project phases students were asked to read and comment the ongoing projects of other learners. The project groups worked independently during three months on their projects. There was one mandatory work package (intermediate milestone) to be performed before the final project has to be published on the wiki. The groups had the opportunity to ask for a group meeting with the teacher and every published project step was visible on the website. Some students published the ongoing project collaboratively using the wiki page as a common workspace. Some students visited the wiki pages of other groups in order to find inspiration for their own work.

A template has been proposed for the publication of the final project with the following elements : 'Title', 'Abstract', 'characteristics of the projects', 'tags', 'amount of lessons', 'infrastructures', 'pupils activities'.

In this setting we used the evaluation widgets (rating and working progress) on two wiki pages per group. First on the page where they describe the concepts of their project and second on the project page, where they present the details of their project and the final project work. We then created a overview page per medium (audio, print, video, image processing). Besides the links on the different pages of the groups also the meta widgets are placed on these overview pages. E.g. the metawidget on the overview page for the medium video shows all ratings and working progress widgets of all groups working with video.

\subsection{Workflow for the teacher}

From a teachers perspective it is important that learners learn to evaluate the quality and the originality of their work and the work of their peers. The rating widget enables all members of the learning community to quickly and easily rate the quality of produced content (pages or even different sections within wiki pages).

In order to create and display such a rating widget on the wiki page teachers have to $\log$ in to the web interface for the evaluation widgets. They then create a rating widget for the project page of every group by entering the name for the widget "project group i", where i denotes the number of a group. This means he/she enters for example the name "project group 1", then he/she clicks on the button "create widget" and then gets the iframe code for that widget. $\mathrm{He} /$ she then goes to the project page of group 1 in the wiki and enters the code there. How this is done in detail depends on the wiki engine used. The widget can be placed anywhere on the page. He/she then repeats the same procedure for all other groups. In the same manner he/she creates widgets for the concept page of every group. Now the rating widgets are ready and installed on the wiki pages of the groups. From now on learners can rate the work of the other groups when they visit their project wiki page.
A second goal of the teacher is, that the learners find the high quality projects and artifacts. Therefore he/she creates a meta widget for every topic. One for audio, showing all ratings of the audio artifacts, one for video, showing all ratings for the video artifacts and one for image processing, showing the ratings of all image artifacts and one for print. To do so, he/she again enters the widget creation web site. There he/she chooses which ratings he/she want to show for example in the video meta widget. Then he/she creates the widget with a mouse click and then copies the provided code on the video overview wiki page. The results of all ratings in the topic video are then showed there. He/she's then doing the same for the audio overview page and so on. Figure 4 shows different views of a meta widget.

The same procedure can be adapted for the creation and placement of the working progress widget on each project and concept page of the learners. Of course it is possible to create a meta widget delivering a view of all rating and working progress widgets (see Figure 4).

Once the project work is launched, it might be interesting for teachers to quickly detect which groups have performed the different tasks determined by the didactic setting. The meta widget may be used as control instrument to find the groups who did not perform the requested work and to provide some specific support. The rating widget may be used to find out which project are well rated by the learning community. Whenever the quality standards of the learning community do not fit the requirements of the teacher he may write some comments of specific pages or give some general information regarding quality issues of the project. The tool permits to react on the ongoing project and has formative character.

\subsection{Workflow for learners}

From a learner's perspective it is important to get inspiration and good ideas for the project. Being able to have a quick overview of quality and work done by other comparable work performed by peers helps them finding quickly the relevant information. When the project work starts, students find an 'empty' rating and working project widget on their project page. When they start creating artifacts and adding text into the wiki they change the status of the working progress widget (see Figure 2). From this moment on the meta widget on the overview page changes its status and permits other learners to see that some work has been performed in a specific group. If one student need some inspiration he visits the project page, reads what has been produced and rates the ideas and the work using the rating tool on top of the page. Of course it is also possible to leave a comment using the comment functionality on the wiki page but the effort is much bigger to write something than just to click on the rating widget and assign one to 5 stars. The more the projects evolve the more students visit pages and rate and the more relevant is the information displayed by the meta widget.

\section{CONCLUSION AND FUTURE WORK}

Two widget types, evaluation and meta widget, has been created and used in a wiki environment for a long term project-based learning setting with over hundred learners. The web widgets help to create a framework for formative evaluation by giving a better overview of performed work and quality of created artifacts within the wiki. The wid- 


\begin{tabular}{|c|c|c|c|c|c|c|c|}
\hline \multicolumn{5}{|c|}{$12 \mathrm{HS}$ - Video } & & & \\
\hline Bereich & Konzept & Projekt & Konzept & Projekt & & & \\
\hline Typ & Bewertung & Bewertung & Meilenstein & Meilenstein & \multicolumn{3}{|c|}{ 12HS - Print } \\
\hline V-1-1_12 & $0 / 10$ & $0 / 10$ & $100 \%$ & $100 \%$ & Bereich & Konzept & Projekt \\
\hline V-1-2_12 & $10 / 10$ & $0 / 10$ & $100 \%$ & $100 \%$ & Typ & Bewertung & Bewertung \\
\hline V-1-3_12 & $0 / 10$ & $10 / 10$ & $100 \%$ & $100 \%$ & P-1-1_12 & $8.5 / 10$ & $8.1 / 10$ \\
\hline V-2-1_12 & $9 / 10$ & $0 / 10$ & $100 \%$ & $100 \%$ & P-1-2_12 & $0 / 10$ & $0 / 10$ \\
\hline V-2-2_12 & $7 / 10$ & $0 / 10$ & $100 \%$ & $100 \%$ & P-1-3_12 & $10 / 10$ & $10 / 10$ \\
\hline V-2-3_12 & $8 / 10$ & $0 / 10$ & $100 \%$ & $100 \%$ & P-1-4_12 & $10 / 10$ & $9.8 / 10$ \\
\hline V-3-1_12 & $0 / 10$ & $0 / 10$ & $100 \%$ & $100 \%$ & P-1-5_12 & $10 / 10$ & $10 / 10$ \\
\hline V-3-2_12 & $8 / 10$ & $10 / 10$ & $0 \%$ & $100 \%$ & P-1-6_12 & $0 / 10$ & $0 / 10$ \\
\hline
\end{tabular}

gets display relevant semantic information to the learning community. By rating other projects and formulating the working progress of their projects learners produce metadata which are computed and visualized in the meta widget. In order to optimize the use of the widget it is important to reduce the 'burden' and the energy for metadata creation and maximizing the outcome of the semantic information for learning processes. In our work learners create the metadata by rating other projects and by formulating which part of a specific task within a project deliverable has been fulfilled. The meta data creation is at the same time an important part of the learning process. By rating other projects the participants have to decide how good other projects are in relation to their own work. This reflective process helps to situate the quality of the personal work and to set it in relation to other projects. By defining the state of work within a project deliverable the learner has to reflect on the task to fulfill and make decision concerning planning goal and totally amount of work to perform. Such a reflexion enhances metacognitive skills of the learners [17].

According to Dylan and Thompson [6] the reflection of the own working progress (situate where the learner is), taking a decision about the quality of other projects and the ability to quickly find and compare the own work with the best rated and mostly achieved other projects (using the meta widget) are part of the framework for formative evaluation and so fruitful for the learning process. Following Saito and Fajita [14] students have favourable attitudes towards peer rating and peer feedback does not influence students favourable attitudes about the feedback.

The proposed evaluation widgets (rating widget and working progress widget) and the meta widget can potentially be used for all large scale, long term technology enhanced collaborative formal and also non formal learning settings, where a collaborative web page helps organizing the course activities. In the recent few years elite Universities like MIT and Cambridge offered such free, multi user open online courses (moocs; [9]).

Using web widgets may enhance retrieval of salient information and check for relevant activities for xmoocs as well as for cmoocs (xmooks: rather instructivism based courses, where a traditional, e.g. lecturing part, course setting is accompanied by an open collaboration element and cmocs: rather connectivism based courses, where the participants collaborate within self organized groups using non predefined social channels [15] [5]. The flexibility of web widgets and the possibility to easily be embedded on each editable website may help visualizing on the central mooc website the quality of activities of different learning groups spread over several collaborative websites and social networks.

\subsection{Future work}

As mentioned above we plan to implement an easy to use web interface for end users, especially teachers where they can create, administer and delete the widgets and meta widgets as well as choose the different views for the master widget. Furthermore we like to implement a tool for statistical analysis and representation of the usage of the widgets, showing when which widget has been edited.

Testing and adapting the usability and the utility of the proposed widgets and creating other widgets will be our further plans as well as testing of evaluation, meta and other types of widgets in different other formal and non formal massive learning environments.

\section{REFERENCES}

[1] P. Black and D. Wiliam. Inside the black box : Raising standards through classroom assessment. Phi Delta Kappan, 80(2):139-148, 1998.

[2] P. Black and D. Wiliam. Developing the theory of formative assessment. Educational Assessment, Evaluation and Accountability (formerly: Journal of Personnel Evaluation in Education), 21:5-31, 2009.

[3] S. Clarke. Targeting Assessment in the Primary Classroom: Strategies for Planning, Assessment, Pupil Feedback and Target Setting. Hodder Arnold, 1998.

[4] B. Döbeli Honegger. Wiki und die starken potenziale. Computer und Unterricht, 17(66):39-41, 2007.

[5] S. Downes. Connectivism and connective knowledge. http://www.huffingtonpost.com/stephen-downes/ connectivism-and-connecti_b_804653.html, January 5, 2011.

[6] W. Dylan and M. Thompson. The Future of Assessment: Shaping Teaching and Learning, chapter Integrating Assessment with Instruction: What Will It Take to Make It Work? Lawrence Erlbaum Associates, 2008 . 
[7] M. Guzdial, J. Rick, and C. Kehoe. Beyond adoption to invention: Teacher-created collaborative activities in higher education. Journal of the Learning Sciences, 10((c) 2002 Inst. For Sci. Info):265-279+, 2001.

[8] B. Leuf and W. Cunningham. The Wiki Way: Quick Collaboration on the Web. Addison-Wesley Professional, Apr. 2001.

[9] T. Levin. Universities abroad join partnerships on the web. The New York Times, February 202013.

[10] M. Notari. How to use a wiki in education: 'wiki based effective constructive learning'. In Proceedings of the 2006 international symposium on Wikis, WikiSym '06, pages 131-132, New York, NY, USA, 2006. ACM.

[11] M. P. Notari and B. Doebeli. Looking Toward the Future of Technology-Enhanced Education: Ubiquitous Learning and the Digital Native, chapter Learning in an active collaborative space, page 20. IGI Global, dec 2009.

[12] M. P. Notari and B. Doebeli Honegger. Wiki an archetypical tool for collaborative learning in the digital age. In S. Bocconi and G. Trentin, editors,
Wiki Supporting Formal and Informal Learning, chapter 2, pages $21-40$. Nova Publisher, New York, USA, 1 edition, 2011.

[13] K. R. Parker and J. T. Chao. Wiki as a Teaching Tool. Interdisciplinary Journal of Knowledge and Learning Objects, 3, 2007.

[14] H. Saito and T. Fujita. Characteristics and user acceptance of peer rating in efl writing classrooms. Language Teaching Research, 8(1):31-54, 2004.

[15] G. Siemens. George siemens on massive open online courses (moocs). http://www . youtube.com/watch?v=VMfipxhT_Co.

[16] M. van Doorn and A. Eliëns. Integrating applications and the world-wide web. Computer Networks and ISDN Systems, 27(6):1105-1110, 1995.

[17] M. Veenman, B. Van Hout-Wolters, and P. Afflerbach. Metacognition and learning: conceptual and methodological considerations. Metacognition and Learning, 1(1):3-14, Apr. 2006.

[18] W3C. Widgets 1.0: The widget landscape (q1 2008). http://www.w3.org/TR/widgets-land/, March 2013. 